\title{
Pax3/Pax7 mark a novel population of primitive myogenic cells during development
}

\author{
Lina Kassar-Duchossoy, ${ }^{1,2}$ Ellen Giacone, ${ }^{1}$ \\ Barbara Gayraud-Morel, Aurélie Jory, \\ Danielle Gomès, and Shahragim Tajbakhsh ${ }^{3}$
}

Stem Cells and Development, Department of Developmental Biology, Pasteur Institute, Centre Nationale de la Recherche Scientifique Unité de Recherche Associeé (CNRS URA) 2578, 75724 Paris, Cedex 15, France

Skeletal muscle serves as a paradigm for the acquisition of cell fate, yet the relationship between primitive cell populations and emerging myoblasts has remained elusive. We identify a novel population of resident $\mathrm{Pax}^{+}$/ $\operatorname{Pax} 7^{+}$, muscle marker-negative cells throughout development. Using mouse mutants that uncouple myogenic progression, we show that these $\mathrm{Pax}^{+}$cells give rise to muscle progenitors. In the absence of skeletal muscle, they apoptose after down-regulation of $\operatorname{Pax} 7$. Furthermore, they mark the emergence of satellite cells during fetal development, and do not require Pax3 function. These findings identify critical cell populations during lineage restriction, and provide a framework for defining myogenic cell states for therapeutic studies.

Supplemental material is available at http://www.genesdev.org.

Received April 1, 2005; revised version accepted May 5, 2005.

An unresolved issue in skeletal muscle development has been the nature of a reserve population of undifferentiated cells that ensures continued prenatal growth of this tissue (Parker et al. 2003; Tajbakhsh 2003). In the early embryo, muscle progenitors and precursors have been described (Tajbakhsh and Buckingham 2000). During post-natal life, satellite cells are the principal regenerative cell type (Zammit and Beauchamp 2001). About $1 \mathrm{~d}$ before birth, the appearance of progenitors associated with fibers has led to the assumption that these cells will give rise to future satellite cells in the adult (Cossu et al. 1993). However, the link between progenitors in the early somite and those observed at birth has remained enigmatic. In addition, the appearance of embryonic and fetal myoblasts has raised questions regarding their relationship with prenatal progenitors and emerging satellite

[Keywords: skeletal muscle stem cells; Pax3/Pax7; myogenic regulatory factors; satellite cells; somite; lineage]

${ }^{1}$ These authors contributed equally to this work.

${ }^{2}$ Present address: CECS/I-Stem, Bât. Généthon, 1 rue de l'Internationale, 91000 Evry, France.

${ }^{3}$ Corresponding author.

E-MAIL shaht@pasteur.fr; FAX 33-1-45-68-89-63.

Article and publication are at http://www.genesdev.org/cgi/doi/10.1101/ gad.345505. cells. Studies in avians had suggested that satellite cells originate from somites, yet the endothelial origin of satellite cells remained unresolved (Armand et al. 1983). Furthermore, recent observations that muscle- or bonemarrow-derived mesenchymal stem cells can give rise to satellite cells or contribute to adult muscle after injury has questioned the notion that satellite cells originate exclusively from somites (Ferrari et al. 1998; Asakura et al. 2002; LaBarge and Blau 2002; Polesskaya et al. 2003). Therefore, in spite of considerable genetic data, cell relationships in the skeletal muscle lineage remain unresolved.

During embryonic development, transitory structures called somites give rise to an epithelial dermomyotome, the source of dermal and endothelial precursors, as well as all the skeletal muscles in the body (Christ and Ordahl 1995; Tajbakhsh and Buckingham 2000). Multipotent muscle progenitor cells (MPCs) arising in the dermomyotome acquire definitive identity via the myogenic regulatory factors (MRFs) Myf5, Mrf4, and Myod (Rudnicki et al. 1993; Tajbakhsh et al. 1996; Kassar-Duchossoy et al. 2004). These progenitors give rise to muscle precursors called myoblasts (Hauschka 1994; Tajbakhsh 2003). Muscle differentiation is subsequently mediated by Myogenin, Myod, and Mrf4 (Tajbakhsh and Buckingham 2000). In the somite, the first skeletal muscle mass to form is the myotome. Skeletal muscle tissue is then established in successive steps by embryonic and fetal myoblasts that fuse to form differentiated primary and secondary fibers, respectively (Bonner and Hauschka 1974; Miller and Stockdale 1986; Cossu et al. 1988; Stockdale 1992; Pin and Merrifield 1993). Embryonic and fetal myoblasts have been reported to have distinct properties (Cossu et al. 1988; Cusella-De Angelis et al. 1994); however, their exclusive contribution to primary and secondary fibers, respectively, has been questioned (Harris et al. 1989; Zhang and McLennan 1995; Dunglison et al. 1999).

To address these issues, we examined genetic mutants that uncouple key steps during myogenic commitment, and at different stages of development. Our observations identify a novel population of cells that express Pax3 and Pax7 and reside in skeletal muscles of the trunk and limbs. Importantly, some do not express muscle markers, and by late fetal stages, they emerge as satellite cells.

\section{Results and Discussion}

\section{Pax3/Pax 7 and MRF expression identify distinct myogenic states in the somite}

From embryonic day 9.75 (E9.75), almost all dermomyotomal cells express Pax3 and Pax7, although Pax3 is expressed at higher levels in the dorsal and ventral dermomyotome lips, whereas Pax7 is preferentially expressed in the central dermomyotome (Fig. 1A,D; Supplementary Fig. 1A,C). Embryonic muscle progenitor cells $\left(\mathrm{MP}_{\mathrm{E}} \mathrm{Cs}\right)$ are born predominantly along the dorsal and ventral dermomyotome lips (arrowheads in Fig. 1C [bottom], E). They express Myf5 and Mrf4 and rapidly give rise to Desmin ${ }^{+}$myoblasts that form the myotome in the somite (Tajbakhsh and Buckingham 2000). A distinct topological distribution of $\mathrm{Pax}^{+}$and $\mathrm{MRF}^{+}$cells, in the dermomyotome and myotome, respectively, is characteris- 


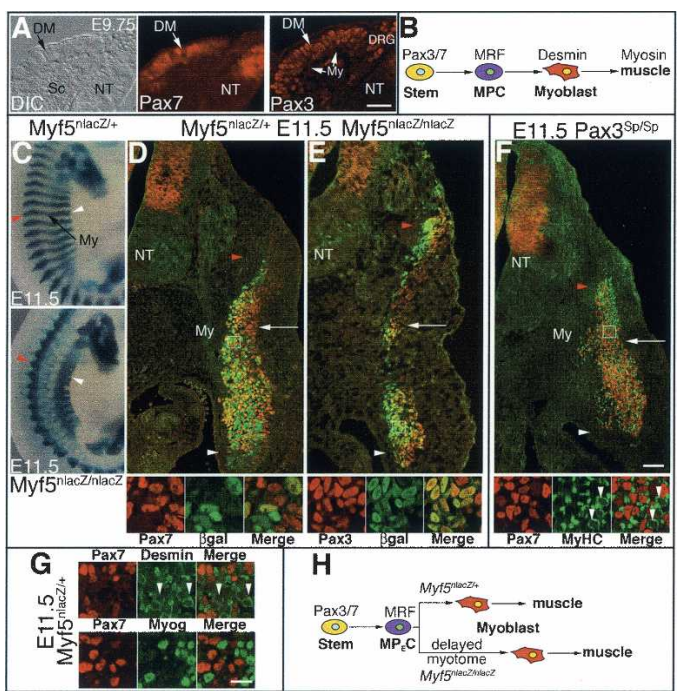

Figure 1. $P a x 3 / P a x 7$ and $M R F$ expression identify distinct cell populations in the somite. (A) Pax3 and Pax7 are coexpressed in almost all dermomyotomal (DM), but not myotomal (My) cells at E9.75; transverse section of interlimb somites. Pax3 also marks dorsal root ganglion (DRG) cells. (B) Scheme representing proposed cell order in skeletal muscle. MRFs (Myf5, Mrf4, Myod) are expressed in embryonic progenitors as well as myoblasts (precursors), but not in the presumed stem cell. $(C)$ X-gal staining of E11.5 Myf $5^{\text {nlacz/+ }}$ and $M y f 5^{\text {nlacz/nlacz }}$ embryos showing absence of a myotome (My) in the latter. $(D-F)$ Immunohistochemistry of cryostat sections of E11.5 embryos showing merged images of antibody stainings in low magnifications (high magnifications are shown in boxed areas). $\mathrm{Pax}^{+}$ cells enter the myotome dorsally ("parachute," arrows). (D) antiPax7, anti- $\beta$ gal stainings show $\mathrm{Pax}^{+} / \beta$-gal ${ }^{-}$cells in the myotome in $M y f 5^{\text {nlacz/+ }}$ embryo as well as coexpression. $(E)$ anti-Pax3, anti- $\beta$ gal stainings show release of the $\mathrm{Pax}^{+}$population into presumed myotome space in the absence of a myotome in $M y f 5^{\text {nlacz/nlacz }}$. Boxed area shows coexpression of Pax 3 and $\beta$-gal in developmentally arrested MPCs in ventral dermomyotome lip in Myf5 $5^{\text {nlacZ/nlacZ }}$. $(F)$ anti-Pax7, anti-MyHC stainings show exclusion in the myotome of

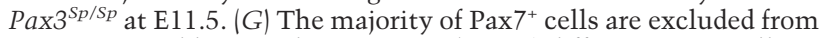
Desmin $^{+}$myoblasts and Myogenin ${ }^{+}$(Myog) differentiating cells at E11.5. (H) Identification of distinct cell states in Myf5 $5^{\text {nlacz/nlacz }}$ embryos. In the absence of Desmin ${ }^{+}$precursors, $\mathrm{Pax}^{+} / \mathrm{MRF}^{-}$(stem) and $\mathrm{Pax}^{+} / \mathrm{MRF}^{+}$(progenitors) are identified in $E$. Images on sections are confocal optical sections. Arrowheads $(C$; low magnifications, $D-F)$ indicate dorsal (red) and ventral (white) dermomyotome. (NT) Neural tube; $(\mathrm{Sc})$ sclerotome; (DIC) differential interference contrast microscopy. Bars: $A, 20 \mu \mathrm{M} ; D-F$, low magnifcations, $50 \mu \mathrm{M} ; D-G$, high magnifications, $10 \mu \mathrm{M}$.

tic of early myotome formation (Tajbakhsh 2003). Pax3/ Pax7-expressing cells in the dermomyotome are cycling, whereas MRF-expressing cells in the myotome are predominantly post-mitotic (Supplementary Fig. 1C; Kahane et al. 2001).

Since other cell types including dermal and endothelial progenitors arise from the dermomyotome, it is not clear if all of the Pax-expressing cells located in this epithelium are the ancestors of MPCs (Christ and Ordahl 1995; Ben-Yair and Kalcheim 2005). Pax3 and Pax7 protein levels normally decline after $M R F$ expression and subsequent release of cells from the dermomyotome, since the majority of myotomal cells are Pax3/7 negative before E10.5 (Fig. 1A; Tajbakhsh et al. 1997; data not shown). To investigate the lineage relationship between $\mathrm{Pax}^{+}$and $\mathrm{MRF}^{+}$cells, we examined embryos in which myogenic commitment was temporally blocked. $\mathrm{MP}_{\mathrm{E}} \mathrm{Cs}$ having activated $M y f 5$ in $M y f 5^{\text {nlacz/nlacz }}$-null embryos remain developmentally arrested until about E11.5 (Fig. 1C,E,H; Supplementary Fig. 1A). Pax3/7 proteins persist in these cells blocked dorsally and ventrally, indicating that the $\mathrm{Pax}^{+}$cells in these regions of the dermomyotome give rise to $\mathrm{MP}_{\mathrm{E}} \mathrm{Cs}$ (Fig. 1E; Supplementary Fig. 1A). These findings, and the observation that a progressive loss of Pax expression was concomitant with a gain in $\beta$-gal expression in normal embryos (Fig. 1D; data not shown), indicate that the majority of Pax-expressing cells originating from the dorsal and ventral dermomyotome lips are part of a lineage continuum with MPCs that express the $M R F s$.

\section{A population of proliferating $\mathrm{Pax}^{+} / \mathrm{Pax} 7^{+}$, muscle marker-negative cells resides in skeletal muscle}

The dermomyotome undergoes a biphasic epithelial to mesenchymal transition, first in its central portion, and subsequently in the lips situated at its extremities from E10.75 in interlimb somites (Fig. 1D; Supplementary Fig. 1A; Tajbakhsh 2003; Ben-Yair and Kalcheim 2005). Importantly, at this stage the spatial separation of Pax- and MRF-expressing cells was lost. $\mathrm{Pax}^{+}$cells released from the central portion of the dermomyotome become dispersed among differentiating myotomal cells (Fig. 1D,G). Immunohistochemistry of $M y f 5^{\text {nlacz/+ }}$ embryos with anti-Pax 7 and anti- $\beta$-gal antibodies revealed that a subpopulation of these cells in the myotome remained $\mathrm{Pax}^{+} / \beta$-gal ${ }^{-}$(Fig. 1D; Supplementary Fig. 1A). This was confirmed with highly sensitive X-gal staining, which marks almost all myotomal cells (Cossu et al. 1996; Tajbakhsh et al. 1996; data not shown). Accordingly, $\mathrm{Pax}^{+}$cells that did not express another myogenic commitment marker, Myod, were observed (data not shown). Furthermore, these $\mathrm{Pax}^{+}$cells did not express the downstream differentiation markers Myogenin and Myosin heavy chain (Fig. 1F,G). Consistent with the hypothesis that these $\mathrm{Pax}^{+}$cells represent an uncommitted reservoir of cells, Pax $3 / 7^{+}, \mathrm{MRF}^{-}$cells in the myotome continued to divide (Supplementary Fig. 1B-D) as they entered the myotome from its dorsal side from E11 (Fig. 1D-F, arrow). We distinguish this novel population from its presumed derivatives, the progenitor $\left(\mathrm{MRF}^{+} / \mathrm{Desmin}^{-}\right)$, and precursor $\left(\mathrm{MRF}^{+} / \mathrm{Desmin}^{+}\right)$cells (Fig. 1B). Since skeletal muscle is a potent source of signaling molecules, we asked if differentiated muscle is necessary for the mobilization of these $\mathrm{Pax}^{+}$cells from the central dermomyotome. In $M y f 5^{\text {nlacz/nlacz }}$ embryos, the early myotome is absent (Fig. 1C,E,H), and it is initiated by Myod from E11.5 (Tajbakhsh et al. 1997). The release of Pax3/7+ cells from the central dermomyotome occurs in the absence of a myotome (Fig. 1E; Supplementary Fig. 1A, arrow).

Muscles in the limbs are established by migratory cells from adjacent somites. In the mouse, Pax3, but not Pax7, plays an essential role in this process since $P a x 3^{S p / S p}$ mutants are devoid of limb muscles (Tajbakhsh et al. 1997; Tajbakhsh and Buckingham 2000). Migrating $\mathrm{Pax}^{+} / \mathrm{MRF}^{-}$cells activate Myf5 and Myod after arrival in the limb from E10.5 (Tajbakhsh and Buckingham 1994). Interestingly, we observed the onset of Pax7 expression in $\mathrm{Pax}^{+}$cells from E11.5 in the limbs. Although most of these cells became $\beta$-gal ${ }^{+}$in $M y f 5^{\text {nlacz/+ }}$ embryos, sensitive X-gal staining revealed that a subpopulation of $\mathrm{Pax}^{+} / \mathrm{Pax}^{+}$cells remained $\mathrm{X}$-gal negative during limb development (Supplementary Fig. 2; data not 


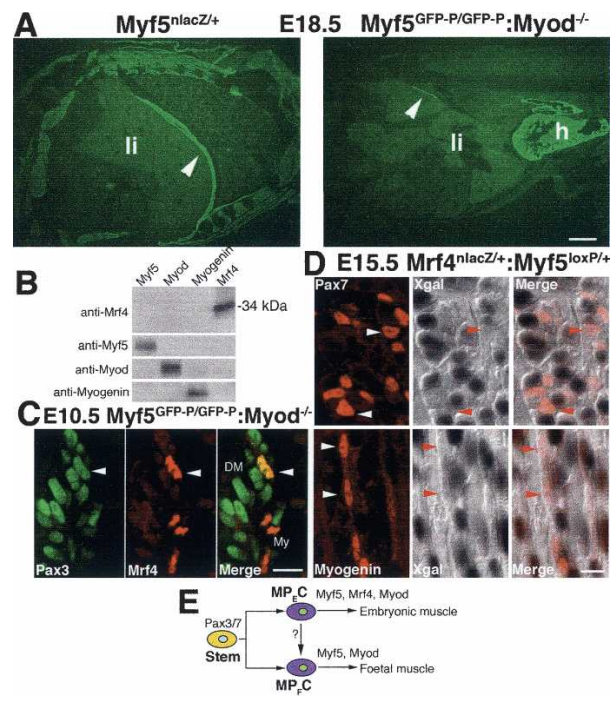

Figure 2. Embryonic and fetal muscle progenitors are genetically distinct. (A) Immunohistochemistry with anti-MyHC antibody shows that fetal skeletal muscles are lacking at E18.5 in $M y f 5^{G F P-P / G F P-P}: \mathrm{Myod}^{-1-}$ mutants (arrowhead, residual embryonic muscle) compared with the Myf5n $5^{\text {nlaczl+ }}$ control (arrowhead, diaphragm). (B) Western blot; anti-Mrf4 antibody does not cross-react with the other MRFs when overexpressed in HEK293T cells. (C) Pax3 and Mrf4 proteins are coexpressed in a nucleus of an embryonic progenitor in the dermomyotome (DM) at E10.5 (arrowhead). $\mathrm{Mrf4}^{+}$cells are also located in the myotome (My). GFP autofluorescence from $M y f 5^{G F P-P}$ is not detected under these fixation conditions. (D) X-gal staining (dark nuclei) of E15.5 Mrf $4^{\text {nlacz/+ }}:$ Myf $5^{\text {loxP/+ }}$ muscles shows that Mrf4 is not coexpressed with Pax 7 (arrowheads) in stem/progenitors in the fetus (see E). Myogenin (arrowheads) is observed in X-gal-negative cells; therefore, $M r f 4$ is expressed later in differentiation. $(E)$ Proposed model for generation of progenitors from stem cells. (h) Heart; (li) liver. Bars: $A, 1 \mathrm{~mm} ; B, C, 10 \mu \mathrm{M}$.

shown). Therefore, also in the limbs, somite-derived muscles retain a population of $\mathrm{Pax}^{+} / \mathrm{MRF}^{-}$cells.

Taken together, our observations indicate that the $\mathrm{Pax}^{+} / \mathrm{MRF}^{-}$population becomes distributed among skeletal muscle masses in the trunk and limbs after the disappearance of the dermomyotome. This novel population might represent a persistent stem cell pool that gives rise to muscle progenitors during development. At later stages, fetal myoblasts emerge, and their relationship with embryonic MPCs and myoblasts remains controversial (Harris et al. 1989; Cusella-De Angelis et al. 1994; Evans et al. 1994; Tajbakhsh 2003). To investigate this issue further, we examined mouse mutants in which the biphasic prenatal myogenic program is uncoupled genetically.

\section{Uncoupling embryonic from fetal myogenesis unveils muscle progenitors and their ancestors}

Remarkably, Myf5:Myod double mutants, generated with either $M y 5^{10 x P}$ or $M y f 5^{G F P-P}$ alleles, make embryonic (Kassar-Duchossoy et al. 2004) but not fetal muscles (Fig. 2A; data not shown). Therefore, Mrf4 can determine muscle progenitor cell identity in the embryo, but not in the fetus. In keeping with this notion, Mrf4 $4^{\text {nlac }}$ is expressed in the dermomyotome of normal embryos (Kassar-Duchossoy et al. 2004), and Pax3 and Mrf4 proteins are coexpressed in embryonic progenitors in the dermomyotome in double mutants (Fig. 2C). Furthermore, $\beta$-gal from the Mrf4 ${ }^{\text {nlac } Z}$ knock-in was not coexpressed with Pax7 in the fetus (Fig. 2D, top). Moreover, expression of the early differentiation marker Myogenin preceded that of Mrf4 $4^{\text {nlacZ }}$ in the fetus (Fig. 2D, bottom). Thus, Mrf4 is expressed in differentiated cells and is not detected in fetal $\mathrm{MP}_{\mathrm{F}} \mathrm{Cs}$, consistent with the finding that fetal muscles are lacking in Myf5:Myod double mutants. These observations demonstrate that $\mathrm{MP}_{\mathrm{F}} \mathrm{Cs}$ in the fetus are genetically distinct from embryonic $\mathrm{MP}_{\mathrm{E}} \mathrm{Cs}$ with respect to their requirement for, or expression of, Mrf4 (Fig. 2E).

We then investigated the relationship between the $\mathrm{Pax}^{+}$cells, progenitors, and precursors in the fetus. Not all $\mathrm{Pax}^{+}$cells derived from the dermomyotome give rise to skeletal muscle (Christ and Ordahl 1995; Kardon et al. 2002), therefore it is important to determine if resident $\mathrm{Pax}^{+}$cells are in the muscle lineage. Antibody stainings for the endothelial marker PECAM failed to detect coexpression with Pax7 in emerging muscle masses, suggesting that the $\mathrm{Pax}^{+}$cells residing in muscle are not in the endothelial lineage (data not shown). In addition, in the chick, Pax7 is not coexpressed with the connective tissue marker TCF4 (Kardon et al. 2003). Figure 3A shows that $\mathrm{Pax}^{+} / \mathrm{Myf5}^{-}$and $\mathrm{Pax}^{+} / \mathrm{Myf5}^{+}$cells reside in fetal muscles. This suggests that as in the embryo, they form a lineage continuum. Accordingly, the majority of

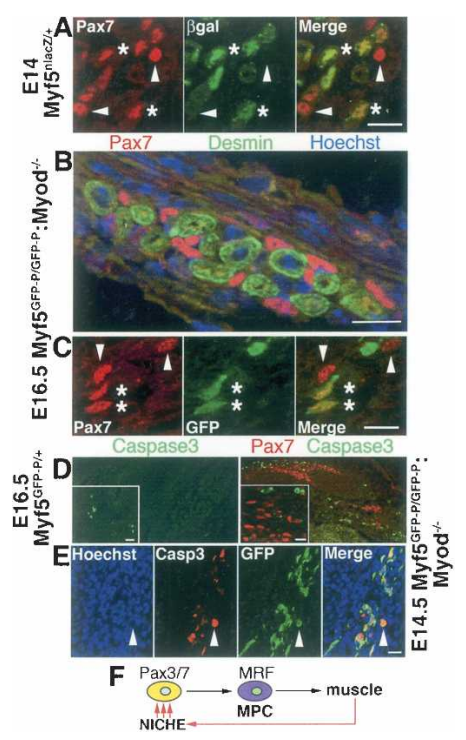

Figure 3. Uncoupling fetal from embryonic myogenesis points to a hierarchical cell order in the muscle lineage. $(A)$ Immunohistochemistry of cryostat sections showing Pax $7^{+} / \beta$-gal ${ }^{-}$cells in trunk muscles of Myf5 $5^{\text {nlacz/+ }}$ embryo at E14 (arrowheads). Asterisks indicate coexpressing cells. (B) Individual $\mathrm{Pax}^{7^{+}} /$Desmin $^{-}$cells (red) are associated with residual intercostal Desmin ${ }^{+}$embryonic fibers in the absence of fetal myogenesis at E16.5 in Myf5 $5^{G F P-P / G F P-P}:$ Myod $^{-/-}$ fetus. $(C)$ Some of these cells are negative with an anti-GFP antibody (arrowheads). Anti-Pax7, anti-GFP stainings reveal coexpression in some MPCs (asterisks). (D) Anti-activated Caspase3 antibody in E16.5 control Myf5 $5^{G F P-P /+}$ (left, intercostal; inset, mesenchyme with apoptotic cells) and E14.5 Myf5 ${ }^{G F P-P / G F P-P}:$ Myod $^{-/-}$fetuses. No apoptotic cells in control muscle, and abundant apoptotic cells in the mutant; the latter shows no colocalization with $\mathrm{Pax}^{+}$cells (see inset, right). (E) Antibodies against activated Caspase 3 and anti-GFP reveal apoptosis in myogenic cells in E14.5 Myf5 GFP-P/GFP-P:Myod ${ }^{-/-}$ fetuses (arrowhead). GFP autofluorescence from $M y f 5^{\text {GFP-P }}$ is not detected under these fixation conditions. $(F)$ Scheme indicating that differentiating skeletal muscles are required for maintenance of the primitive myogenic cells. Bars, $10 \mu \mathrm{M}$. 
$\mathrm{Pax}^{+}$cells activate $M y f 5$ as development proceeds (see below), and they are monodispersed and intimately associated with muscle fibers (Figs. 2D [top], 3B). Furthermore, as observed in the embryo (Fig. 1G), Pax expression was down-regulated during committment and differentiation. Since muscle progenitors transit to myoblasts rapidly, it was difficult to distinguish the different myogenic cell populations in the fetus. Therefore, it is desirable to block muscle commitment and investigate the remaining undetermined myogenic cells. To do this, we examined $P a x 3^{S p / S p}: M y f 5^{\text {nlacZ/nlacZ }}$ mutants in which embryonic and fetal myogenesis are compromised in the body (Tajbakhsh et al. 1997), and $M y f 5^{G F P-P / G F P-P}:$ Myod $^{-1-}$ mutants, in which fetal myogenesis is compromised (Fig. 2A). In both models, undifferentiated Desmin ${ }^{+}$cells were not observed in the late fetus, indicating that fetal myoblasts are absent (Table 1; Supplementary Fig. 3B,C). Figure 3C shows that $\mathrm{Pax}^{+} /$ Myf5 $5^{-}$as well as $\mathrm{Pax}^{+} / \mathrm{Myf5}^{+}$cells were detectable in the absence of myoblasts. They appeared in close proximity, and in some cases the $\mathrm{Pax}^{+}$cells were associated with residual Desmin ${ }^{+}$differentiated embryonic fibers (Fig. 3B; Supplementary Fig. 3A). By analogy with the embryo, we propose that $\mathrm{Pax}^{+} / \mathrm{Myf5}^{+}$cells are fetal progenitors $\left(\mathrm{MP}_{\mathrm{F}} \mathrm{Cs}\right)$ and distinguish them from their descendant precursor myoblasts, and their $\mathrm{Pax}^{+} / \mathrm{Myf5}^{-}$ancestors (Fig. 1B). Taken together, these observations suggest that $\mathrm{MP}_{\mathrm{F}} \mathrm{Cs}$ observed in the fetus are generated independently from $\mathrm{MP}_{\mathrm{E}} \mathrm{Cs}$, presumably from persistent $\mathrm{Pax}^{+} / \mathrm{MRF}^{-}$cells. Alternatively, $\mathrm{MP}_{\mathrm{E}} \mathrm{Cs}$ would persist during fetal stages, and thereafter down-regulate Mrf4 expression (Fig. 2E). The latter is less likely since activation of the myogenic factors is generally associated with rapid acquisition of a myoblast identity (Molkentin and Olson 1996; Tajbakhsh and Buckingham 2000). Furthermore, we observe proliferating $\mathrm{Pax}^{+}$cells seeded in muscle masses throughout development. As in the embryo, a progressive loss of Pax expression was concomitant with a gain in $\beta$-gal expression in normal and mutant fetuses, thereby favoring the idea of myogenic progression from $\mathrm{Pax}^{+} / \mathrm{MRF}^{-}$to $\mathrm{Pax}^{-} / \mathrm{MRF}^{+}$cells. Therefore, we propose that the $\mathrm{Pax}^{+} / \mathrm{MRF}^{-}$cells that we identify are ancestral stem cells at the top of a lineage hierarchy, and that they give rise to muscle progenitors during early and mid-development.

Loss of myogenic cells by apoptosis in the absence of skeletal muscle

Surprisingly, diminishing numbers of myogenic cells were observed in double mutants lacking skeletal muscle. Interestingly, these were lost earlier, by E13 in $P a x 3^{S p / S p}:$ Myf5 $5^{\text {nlacz/nlacz }}$ mutants in which all body muscles are missing, compared with E17.5 in $M y f 5^{\text {GFP-P/GFP-P }}$ Myod $^{-/-}$mutants, in which fetal muscles are lacking (Table 1). These observations suggest that in the latter, embryonic muscles sustain the primitive myogenic cells.

To investigate the mechanism of this loss, we assayed for the expression of the activated form of Caspase3, an early marker for apoptosis. Unlike normal fetuses, in the trunk and limbs of double mutants, we observed high numbers of apoptotic cells in presumed muscle-forming regions, as identified by Pax 7 protein or Myf5 reporter gene expression (Fig. 3D,E). Surprisingly, Pax7 and activated Caspase 3 were not coexpressed in double mutants lacking muscle $\left(<1 \% ; n=500 \mathrm{Pax}^{+}\right.$cells) or controls $\left(<1 \% ; n=400 \mathrm{Pax}^{+}\right.$cells). In contrast, a significantly high proportion of $\mathrm{Myf}^{+}$cells coexpressed this marker (at least $20 \% ; n=90 \mathrm{GFP}^{+}$cells) (Fig. 3E; Supplementary Fig. 3B,C; fetal progenitors and embryonic differentiated cells) compared with controls $(<1 \%, n=1000$ cells). This finding demonstrates that $\mathrm{Pax}^{+}$cells are refractory to apoptosis. We suggest that during lineage progression in these mutants, Pax7 protein levels decline after Myf5 expression (Fig. 3A; Supplementary Fig. 1A; data not shown). In the absence of Myf5 and Myod proteins, these progenitors are subsequently lost by programmed cell death, or they change fate (Tajbakhsh et al. 1996). Thus, these findings identify differentiating skeletal muscle as a critical mediator of the survival of myogenic stem/ progenitor cells by maintaining $\operatorname{Pax} 7$ expression, probably via paracrine mechanisms.

Persistent Pax cells mark emerging satellite cells,
and they do not require Pax3 function

The origins of satellite cells have been the subject of much debate (Zammit and Beauchamp 2001; Parker et al. 2003; Tajbakhsh 2003). Since we observed that proliferating $\mathrm{Pax}^{+}$cells reside in muscle throughout development (Fig. 4A,B; Supplementary Fig. 1C,D), we asked if they would persist until birth, and how this population relates to satellite cells. At later fetal stages, $\mathrm{Pax} 7^{+}$cells persisted, whereas Pax3 for the most part was downregulated in these cells (Fig. 4; data not shown). Figure $2 \mathrm{D}$ shows that $\mathrm{Pax}^{+}$cells are loosely associated with differentiating muscle fibers at E15.5. By E16.5 they were located underneath a basal lamina and were situated outside the fiber (Fig. 4A,B), a characteristic feature of satellite cells (Zammit and Beauchamp 2001). Some of these cells could be distinguished from $\mathrm{MRF}^{+} / \mathrm{Desmin}^{+}$

Table 1. Blocking myogenic commitment at different developmental stages in double mutants reveals different classes of myogenic cells

\begin{tabular}{|c|c|c|c|c|c|c|c|}
\hline \multirow[b]{2}{*}{ Genotype } & \multicolumn{3}{|c|}{ Embryo } & \multicolumn{3}{|c|}{ Fetus } & \multirow[b]{2}{*}{ Satellite } \\
\hline & $\mathrm{Pax}^{+} / \mathrm{MRF}^{-}$ & Progenitors & Precursors & $\mathrm{Pax}^{+} / \mathrm{MRF}^{-}$ & Progenitors & Precursors & \\
\hline Wild type; Myf5 $5^{\text {nlacz/+ }}$ & + & + & + & + & + & + & + \\
\hline $\mathrm{Pax} 3^{\mathrm{Sp} / \mathrm{Sp}} ; \mathrm{Pax}^{\mathrm{Sp} / \mathrm{Sp}}: \mathrm{Myf}^{\text {nlacz/+ }}$ & + & + & + & + & + & + & + \\
\hline${ }^{\mathrm{a}} \mathrm{Pax} 3^{\mathrm{Sp} / \mathrm{Sp}}: \mathrm{Myf} 5^{\text {nlacz/nlacz }}$ & $+($ lost E13) & $+($ lost E13) & - & - & - & - & ND \\
\hline Myf5 ${ }^{\text {GFP-P/GFP-P }}:$ Myod $^{-/-}$ & + & + & + & $+($lost E17.5) & $+($lost E17.5) & - & - \\
\hline Myf5 $5^{10 x P / l o x P}:$ Myod $^{-/-}$ & + & + & + & (ND) & (ND) & - & - \\
\hline
\end{tabular}

${ }^{a}$ muscles in the body, but not head, are lacking (Tajbakhsh et al. 1997)

(ND) Not done. 


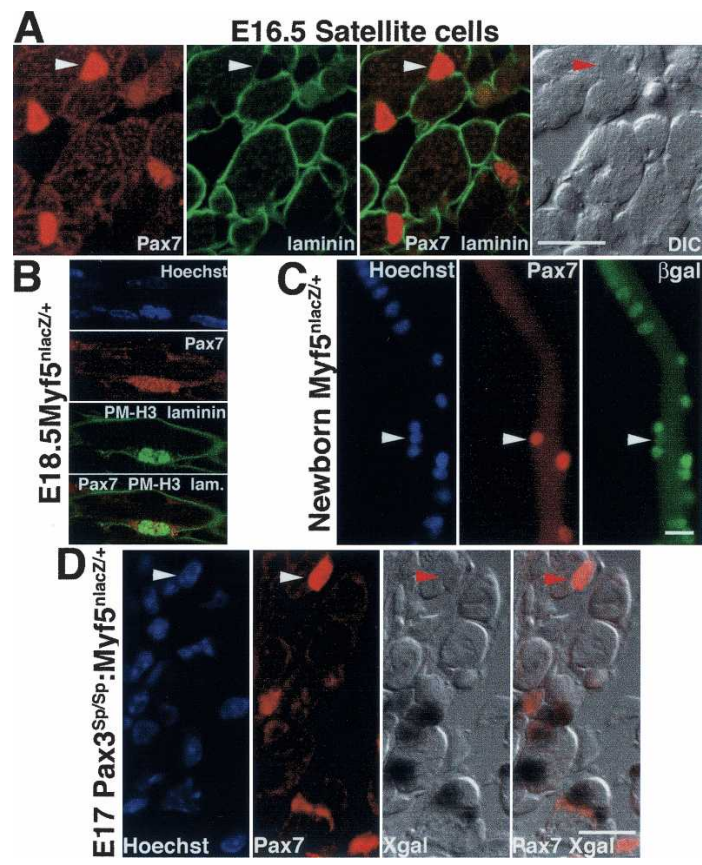

Figure 4. Resident $\mathrm{Pax} 7^{+}$cells mark the emergence of satellite cells and do not require Pax3. (A) Immunohistochemistry of cryostat sections shows $\mathrm{Pax}^{+}$(anti-Pax7; arrowhead) cells associated with the muscle fiber by anti-laminin (green) staining in trunk muscles of $M y f 5^{G F P-P /+}$ fetus at E16.5. (B) E18.5 Pax7 ${ }^{+}$satellite cell in trunk muscle coexpressing the cell proliferation marker PM-Histone3 (green). (C) Freshly isolated forelimb fiber from a Myf5 $5^{\text {nlacz/+ }}$ newborn shows a $\mathrm{Pax}^{+} / \beta$-gal ${ }^{-}$satellite cell. On section and single fibers at birth, this fraction comprises $<1 \%$ of mononucleated $\beta$-gal ${ }^{-}$cells. (D) $\mathrm{Pax}^{+}$satellite cells at $\mathrm{E} 17$ in $\mathrm{Pax}^{\mathrm{Sp} / S p}: M y f 5^{\text {nlacZ/+ }}$ mutant. Some remain X-gal (dark nuclei) negative (arrowhead). Bars, $10 \mu \mathrm{M}$.

fetal myoblasts (Fig. 4C,D; data not shown). Interestingly, by birth we observed that some $\operatorname{Pax} 7^{+}$satellite cells remained negative for, or expressed low levels of, Myf5 $5^{\text {nlacz }}$ (Fig. 4C,D). Albeit, $>99 \%$ of $\mathrm{Pax}^{+}$cells expressed Myf5 around birth (data not shown). These findings suggest that $\mathrm{Pax}^{+} / \mathrm{MRF}^{-}$cells in the fetus are distinct from fetal progenitors and committed precursors, and are lineage descendants of the dermomyotome. Strikingly, $\operatorname{Pax}^{+}$satellite cells were absent at birth in mutants lacking skeletal muscles (Table 1). Taken together, these observations strongly suggest that satellite cells arise from the resident $\mathrm{Pax}^{+}$cells that we identify, thereby supporting the argument against an independent lineage origin for satellite cells.

Pax3 plays a critical role in myogenesis since Pax3null mice lack migratory muscle progenitors, and mice null for Pax3, Myf5, and Mrf4 fail to activate Myod in the body (Tajbakhsh et al. 1997; Kassar-Duchossoy et al. 2004). In addition, dermomyotome integrity is compromised in Pax3-null embryos, whereas Pax 7 mutants do not display overt prenatal muscle deficiencies (Mansouri et al. 1996). Since most Pax3-null mice die by E14.5, the role of Pax3 in fetal muscle development has not been evaluated. We asked whether Pax3 function is required for the emergence of uncommitted $\mathrm{Pax}^{+}$cells in the embryo, or their maintenance. Analysis of $P a x 3^{S p / S p}$ mutants at E11.5 revealed that $\mathrm{Pax}^{+}$cells penetrated the myotome as observed in normal embryos (Fig. 1D,F). Since some $\mathrm{Pax}^{S p / S p}$ mutants survive beyond E14.5, we examined fetuses between E17 and birth. As in normal fetuses, $\operatorname{Pax}^{+}$satellite cells emerged before birth, and some remained $M y f 5^{\text {nlacz }}$ negative (Fig. 4D; data not shown). Thus, the $\mathrm{Pax}^{+}$ancestors of MPCs do not have an absolute requirement for Pax3 for their maintenance, or the generation of embryonic and fetal MPCs and satellite cells.

The classification of different cell states in muscle, notably the identification of a novel uncommitted Pax3/ $\operatorname{Pax} 7^{+}$population, provides a framework for refining the cell order in this lineage, and characterizing the skeletal muscle niche. Moreover, we propose that differentiated skeletal muscle or precursor cells are a functional component of this niche since $\mathrm{Pax}^{+}$stem cells, as well as MPCs, require the downstream myogenic program for their self-renewal, but surprisingly, not for their birth (Figs. 1E, 3F). In future studies it would important to identify factors secreted by skeletal muscle that will mediate the self-renewal of engrafted cells, and thereby enhance their regenerative potential.

\section{Materials and methods}

Preparation of embryos

Mouse mutants were genotyped and interbred, and embryos were prepared as described previously (Kassar-Duchossoy et al. 2004). Briefly, embryos were fixed in $4 \%$ paraformaldehyde, embedded in $15 \%$ sucrose/ $7 \%$ gelatin or in $30 \%$ sucrose, and frozen in liquid nitrogen or isopentane. Cryostat sections 10-20 $\mu \mathrm{m}$ were treated with antibodies or stained with X-gal (Tajbakhsh et al. 1997).

\section{Immunofluorescence and imaging}

For immunofluorescence (Kassar-Duchossoy et al. 2004), the antibodies used were Myf5 (C-terminal, Santa Cruz, polyclonal, 1/800), Mrf4 (Myf6 C-terminal, Santa Cruz, polyclonal, 1/200), Myogenin (F5D, monoclonal, 1/20), Pax7 (monoclonal, 1/20), and Pax3 (monoclonal, 1/200) from Developmental Studies Hybridoma Bank (NICHD), Pax3 (polyclonal, 1/200; kindly provided by J. Epstein, University of Pennsylvania, Philadelphia, PA), Myod (Dako, monoclonal, 1/20), phospho-met-Histone H3 (PM polyclonal, 1/5000; kindly provided by B. Mateescu, Institut Pasteur, Paris, France) (Mateescu et al. 2004); $\beta$-gal (polyclonal, 1/200, kindly provided by O. Puijalon, Institut Pasteur, Paris, France), Ki67 (monoclonal, 1/100, BD Pharmingen), Myosin heavy chain (polyclonal, 1/400; kindly provided by G. Cossu, Stem Cell Research Institute, Milan, Italy), Desmin (monoclonal, 1/100, Dako), laminin (polyclonal, 1/200, Sigma), GFP (polyclonal, 1/200, AbCam), and activated Caspase-3 (polyclonal, 1/200; Cell Signaling). Secondary antibodies were AlexaFluor 488 and 594 (Molecular Probes). Amplification of some monoclonal antibodies was done using a biotin-conjugated anti-mouse antibody (1/1000) followed by Cy3-conjugated Strepavidin (1/2000, Jackson Immunoresearch). All images on sections were acquired with an Apotome-equipped Zeiss Axioplan and Axiovision software. Optical slice views $(0.7-1.1 \mu \mathrm{m})$ were reconstructed from fluorescent samples, using a series of grid projections. All images were assembled in Adobe Photoshop.

\section{Single fiber preparations}

Single fibers were prepared as described previously (Zammit et al. 2002). Briefly, after removal of the skin, forelimbs of newborn pups were digested for 45 min with $0.1 \%$ type I collagenase (Sigma) in DMEM. Single myofibers were released by trituration of the limb with a Pasteur pipette, and fibers were fixed immediately in $1 \%$ PFA for 15 min, rinsed in PBS, and prepared for immunostaining.

\section{Western blot}

MRF-expressing vectors (EMSV-Myf5, EMSV-Myod, EMSV-Myogenin, and EMSV-Mrf4) were transiently transfected in HEK293T cells with Lipofectamine 2000, according to the manufacturer's instructions (Invitrogen) as described (Kassar-Duchossoy et al. 2004). After 48 h, cells were lysed and processed with antibodies (anti Myf-5, C-term, 1/500; antiMyod, full length, 1/200; anti-Myogenin, full length, 1/400; and antiMrf4, C-term, 1/500; Santa Cruz). 


\section{Note added in proof}

Related studies by Relaix et al. (2005) and Gros et al. (2005) appeared in Nature online April 2005 when this manuscript was under review.

\section{Acknowledgments}

We thank L. Heslop and T. Partridge for guidance in preparing single fibers; P. Flamant for technical help; and J. Epstein, B. Mateescu, O. Puijalon, and G. Cossu for reagents. This work was supported by grants from the Pasteur Institute, HFSPO, AFM, ARC, Pasteur GPH, and AFM/ INSERM "Cellules Souches" programs, and EuroStemCell (EU Framework 6 project LHSB-CT-2003-503005).

\section{References}

Armand, O., Boutineau, A.M., Mauger, A., Pautou, M.P., and Kieny, M. 1983. Origin of satellite cells in avian skeletal muscles. Arch. Anat. Microsc. Morphol. Exp. 72: 163-181.

Asakura, A., Seale, P., Girgis-Gabardo, A., and Rudnicki, M.A. 2002. Myogenic specification of side population cells in skeletal muscle. J. Cell Biol. 159: 123-134.

Ben-Yair, R. and Kalcheim, C. 2005. Lineage analysis of the avian dermomyotome sheet reveals the existence of single cells with both dermal and muscle progenitor fates. Development 132: 689-701.

Bonner, P.H. and Hauschka, S.D. 1974. Clonal analysis of vertebrate myogenesis. I. Early developmental events in the chick limb. Dev. Biol. 37: 317-328.

Christ, B. and Ordahl, C.P. 1995. Early stages of chick somite development. Anat. Embryol. 191: 381-396.

Cossu, G., Ranaldi, G., Senni, M.I., Molinaro, M., and Vivarelli, E. 1988. 'Early' mammalian myoblasts are resistant to phorbol ester-induced block of differentiation. Development 102: 65-69.

Cossu, G., Cusella-De Angelis, M.G., De Angelis, L., Mezzogiorno, A., Murphy, P., Coletta, M., Vivarelli, E., Bouché, M., and Molinaro, M. 1993. Multiple myogenic cell precursors and their possible role in muscle histogenesis. In Neuromuscular development and disease (eds. A.M. Kelly and H.M. Blau), pp. 183-194. Raven Press, New York.

Cossu, G., Kelly, R., Tajbakhsh, S., Donna, S.D., Vivarelli, E., and Buckingham, M. 1996. Activation of different myogenic pathways: myf-5 is induced by the neural tube and MyoD by the dorsal ectoderm in mouse paraxial mesoderm. Development 122: 429-437.

Cusella-De Angelis, M.G., Molinari, S., Donne, A.D., Coletta, M., Vivarelli, E., Bouche, M., Molinaro, M., Ferrari, S., and Cossu, G. 1994. Differential response of embryonic and fetal myoblasts to TGF $\beta$ : A possible regulatory mechanism of skeletal muscle histogenesis. Development 121: 637-649.

Dunglison, G.F., Scotting, P.J., and Wigmore, P.M. 1999. Rat embryonic myoblasts are restricted to forming primary fibers while later myogenic populations are pluripotent. Mech. Dev. 87: 11-19.

Evans, D., Baillie, H., Caswell, A., and Wigmore, P. 1994. During fetal muscle development, clones of cells contribute to both primary and secondary fibers. Dev. Biol. 162: 348-353.

Ferrari, G., Cusella-De Angelis, G., Coletta, M., Paolucci, E., Stornaiuolo, A., Cossu, G., and Mavilio, F. 1998. Muscle regeneration by bone marrow-derived myogenic progenitors. Science 279: 1528-1530.

Gros, J., Manceau, M., Thome, V., and Marcelle, C. 2005. A common somitic origin for embryonic muscle progenitors and satellite cells. Nature. [Epub ahead of print April 20.]

Harris, A.J., Duxson, M.J., Fitzsimons, R.B., and Rieger, F. 1989. Myonuclear birthdates distinguish the origins of primary and secondary myotubes in embryonic mammalian skeletal muscle. Development 107: 771-784.

Hauschka, S.D. 1994. The embryonic origin of muscle. In Myology (eds. E.A.G. Engel and C. Franzini-Armstrong), pp. 3-74. McGraw Hill, New York.

Kahane, N., Cinnamon, Y., Bachelet, I., and Kalcheim, C. 2001. The third wave of myotome colonization by mitotically competent progenitors: Regulating the balance between differentiation and proliferation during muscle development. Development 128: 2187-2198.

Kardon, G., Campbell, J.K., Tabin, C.J., Ahima, R.S., and Khurana, T.S. 2002. Local extrinsic signals determine muscle and endothelial cell fate and patterning in the vertebrate limb. Dev. Cell 3: 533-545

Kardon, G., Harfe, B.D., and Tabin, C.J. 2003. A Tcf4-positive mesodermal population provides a prepattern for vertebrate limb muscle patterning. Dev. Cell 5: 937-944.

Kassar-Duchossoy, L., Gayraud-Morel, B., Gomès, D., Rocancourt, D., Buckingham, M., Shinin, V., and Tajbakhsh, S. 2004. Mrf4 determines skeletal muscle identity in Myf5:Myod double-mutant mice. Nature 431: 466-471.

LaBarge, M.A. and Blau, H.M. 2002. Biological progression from adult bone marrow to mononucleate muscle stem cell to multinucleate muscle fiber in response to injury. Cell 111: 589-601.

Mansouri, A., Stoykova, A., Torres, M., and Gruss, P. 1996. Dysgenesis of cephalic neural crest derivatives in $\mathrm{Pax}^{-/-}$mutant mice. Development 122: 831-838.

Mateescu, B., England, P., Halgand, F., Yaniv, M., and Muchardt, C. 2004. Tethering of HP1 proteins to chromatin is relieved by phosphoacetylation of histone H3. EMBO Rep. 5: 490-496.

Miller, J.B. and Stockdale, F.E. 1986. Developmental regulation of the multiple cell lineages of the avian embryo. J. Cell Biol. 103: $2197-$ 2208.

Molkentin, J.D. and Olson, E.N. 1996. Defining the regulatory networks for muscle development. Curr. Opin. Genet. Dev. 6: 445-453.

Parker, M.H., Seale, P., and Rudnicki, M.A. 2003. Looking back to the embryo: Defining transcriptional networks in adult myogenesis. Nat. Rev. Genet. 4: 497-507.

Pin, C.L. and Merrifield, P.A. 1993. Embryonic and fetal rat myoblasts express different phenotypes following differentiation in vitro. Dev. Genet. 14: 356-368.

Polesskaya, A., Seale, P., and Rudnicki, M.A. 2003. Wnt signaling induces the myogenic specification of resident $\mathrm{CD} 45^{+}$adult stem cells during muscle regeneration. Cell 113: 841-852.

Relaix, F., Rocancourt, D., Mansouri, A., and Buckingham, M. 2005. A Pax3/Pax7-dependent population of skeletal muscle progenitor cells. Nature. [Epub ahead of print April 20.]

Rudnicki, M.A., Schneglesberg, P.N.J., Stead, R.H., Braun, T., Arnold, H.-H., and Jaenisch, R. 1993. MyoD or myf-5 is required for the formation of skeletal muscle. Cell 75: 1351-1359.

Stockdale, F.E. 1992. Myogenic cell lineages. Dev. Biol. 154: 284-298.

Tajbakhsh, S. 2003. Stem cells to tissue: Molecular, cellular and anatomical heterogeneity in skeletal muscle. Curr. Opin. Genet. Dev. 13: 412-422.

Tajbakhsh, S. and Buckingham, M.E. 1994. Mouse limb muscle is determined in the absence of the earliest myogenic factor myf-5. Proc. Nat1. Acad. Sci. 91: 747-751.

- 2000. The birth of muscle progenitor cells in the mouse: Spatiotemporal considerations. Curr. Top. Dev. Biol. 48: 225-268.

Tajbakhsh, S., Rocancourt, D., and Buckingham, M. 1996. Muscle progenitor cells failing to respond to positional cues adopt non-myogenic fates in myf-5 null mice. Nature 384: 266-270.

Tajbakhsh, S., Rocancourt, D., Cossu, G., and Buckingham, M. 1997. Redefining the genetic hierarchies controlling skeletal myogenesis: Pax-3 and Myf-5 act upstream of MyoD. Cell 89: 127-138.

Zammit, P. and Beauchamp, J. 2001. The skeletal muscle satellite cell: Stem cell or son of stem cell? Differentiation 68: 193-204.

Zammit, P.S., Heslop, L., Hudon, V., Rosenblatt, J.D., Tajbakhsh, S., Buckingham, M.E., Beauchamp, J.R., and Partridge, T.A. 2002. Kinetics of myoblast proliferation show that resident satellite cells are competent to fully regenerate skeletal muscle fibers. Exp. Cell Res. 281: 39-49.

Zhang, M. and McLennan, I.S. 1995. During secondary myotube formation, primary myotubes preferentially absorb new nuclei at their ends. Dev. Dyn. 204: 168-177. 


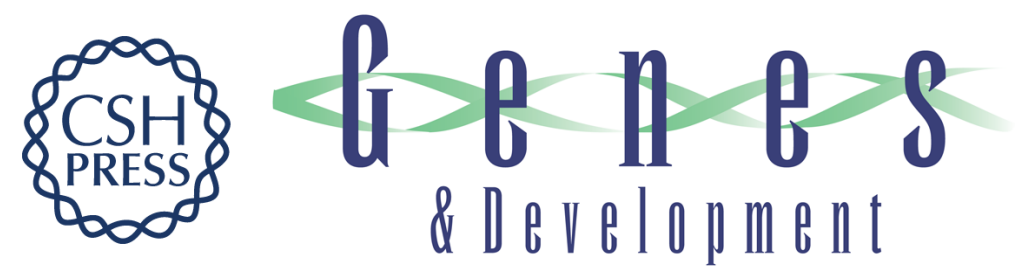

\section{Pax3/Pax7 mark a novel population of primitive myogenic cells during development}

Lina Kassar-Duchossoy, Ellen Giacone, Barbara Gayraud-Morel, et al.

Genes Dev. 2005, 19:

Access the most recent version at doi:10.1101/gad.345505

\section{Supplemental http://genesdev.cshlp.org/content/suppl/2005/06/08/19.12.1426.DC1 Material}

References This article cites 34 articles, 9 of which can be accessed free at: http://genesdev.cshlp.org/content/19/12/1426.full.html\#ref-list-1

\section{License}

Email Alerting

Receive free email alerts when new articles cite this article - sign up in the box at the top Service 